NEWS

\title{
Lab-animal battle reaches truce
}

\section{Biomedical scientists say revised European directive on animal welfare averts feared disaster for research.}

After more than a decade of pitched battles between research advocates and animal-rights campaigners, European Union (EU) legislators have finally agreed on a new legal framework to regulate the use of animals in research.

A closed-door meeting between representatives of the European Commission, the European Parliament and the European Council (respectively, the EU's executive and two legislative bodies) reached a compromise on a directive covering the protection of animals used for scientific purposes (86/609/EEC) on 7 April. The directive must still be ratified by the parliament and council, but this is likely to happen without further debate by July.

Previous drafts of the directive had seemed set to severely hamper European biomedical research, by placing significant restrictions on invasive studies using primates, for example (see Nature 456, 281-282; 2008). But the final directive has largely diffused scientists' concerns. Basic research using primates will now be allowed, for example, and animals will not have to be destroyed immediately after research procedures that cause "moderate" discomfort, as previous forms of the directive had decreed. Instead, the animals can be used in other procedures. At the same time, the draft addresses concerns about animal welfare by introducing minimum cage sizes and other measures.

"It is a political document, a compromise text," says Stefan Treue, director of the German Primate Centre in Göttingen.

"But it could have been worse and we can live with it."

"The compromise that has been reached is something we can live with," agrees Kirsty Reid of the Brussels-based animalwelfare lobby group Eurogroup for Animals, adding that she still regrets the many exemptions to bans on several types of research.

The legislation was designed to update 1986 rules for protecting research animals and to harmonize regulations across the EU. Political discussions began in 1998, and in 2002 the European Parliament mandated the commission to write a draft also taking into account the EU's new commitment to the reduction, replacement and refinement of animal tests.

The commission draft that eventually emerged in November 2008 alarmed both academic researchers and the pharmaceutical industry by proposing extreme restrictions on research and increasing bureaucratic demands

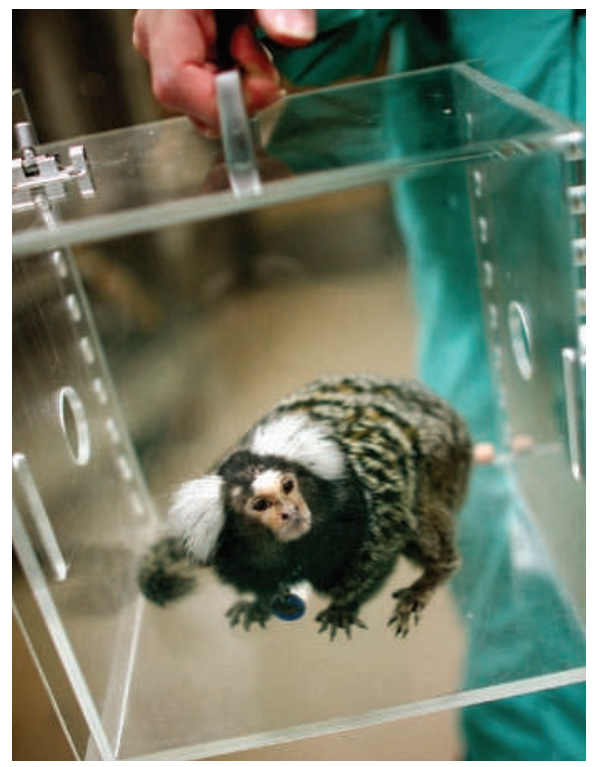

A minimum cage size for research animals is one factor addressed in proposed EU legislation.

on researchers. For example, it banned research on non-human primates unless it was directly applicable to the treatment of "life-threatening or debilitating human conditions", thus blocking basic research, particularly on the brain.

Its scope was so broad that it forbade the scientific use of hens' eggs, essential for vaccine production. And in insisting that animals be destroyed after an experiment causing mild discomfort, it would have dramatically increased the number of animals used in research.

"That draft was a big wakeup call to the scientific community, which didn't lobby enough at the right time," says Simon Festing, chief executive of the London-based research lobby group Understanding Animal Research. Instead, he claims, the commission was exposed to the emotionally powerful influence of the well-organized animal-welfare and anti-vivisection lobby.

But in 2009, research organizations swung into action to persuade parliament to be more sympathetic to their point of view. In its first parliamentary reading in May 2009, most of the controversial restrictions in the draft directive had been removed (see Nature 459, 139; 2009). But the new parliament added a clause of its own, requiring sharing of data generated on animals. Drug-development companies pointed out that this would be difficult for them to comply with, given that much of this information is proprietary intellectual property.

The battle continued through 2009 as the amended draft was discussed by the European Council, which comprises representatives of the EU's 27 member states, many of which considered it too liberal towards researchers. After a new parliament was elected last June, the animal-welfare lobby pounced on new members, convincing many to argue for further restrictions, says Julian Böcker, parliamentary assistant to directive rapporteur Elisabeth Jeggle. "I'd like to be able to convey just how hard we had to fight to maintain research-friendliness in the directive," says Böcker.

\section{Endangered experiments}

The outcome is less than perfect, but at least animal research will be possible, says an administrator at the DFG, Germany's largest grantgiving agency. The directive does ban some forms of research - those involving great apes or causing extreme and prolonged pain. But researchers can appeal for an exemption, on grounds of clinical urgency, through a special committee to be set up in Brussels.

The final draft of the directive also allows experiments on endangered species, such as the barn owl (Tyto alba), which is bred in captivity specifically for auditory research. Procedures for project applications and evaluations are more streamlined than in earlier drafts, and the bureaucratic burden should not increase for researchers from countries in which rules are already strict, such as Britain, Germany and France. Mandatory sharing of animal-research data has also been dropped.

But some scientists are still worried that problems could arise when the loosely worded directive is translated into more tightly worded national laws, which will have to specify, for example, which types of experiment are considered to cause "long-lasting, severe pain". Others maintain that an outright ban on some types of studies clashes with Europe's constitutional duty to carry out research, as enshrined in the Lisbon Treaty, adopted in December 2009.

And physiologist Rainer Nobiling of the University of Heidelberg in Germany worries that restrictions on the use of non-human primates might encourage more testing of experimental therapies in humans, against the Nuremberg code of research ethics.

Alison Abbott 